\title{
Calagem e adubação orgânica na produção de biomassa e óleo essencial em Lippia citriodora Kunth
}

\author{
SOUZA, M.F.; SOUZA JUNIOR, I.T; GOMES, P.A.; FERNANDES, L.A.*; MARTINS, E.R.; COSTA, C.A.; SAMPAIO, \\ R.A. \\ Instituto de Ciências Agrárias / Universidade Federal de Minas Gerais - ICA/UFMG, Avenida Universitária, 1000, \\ Caixa Postal 135, CEP: 39404-006, Montes Claros-Brasil *larnaldo@nca.ufmg.br
}

\begin{abstract}
RESUMO: O presente trabalho objetivou avaliar a calagem e adubação orgânica na produção de biomassa e óleo essencial em Lippia citriodora Kunth. O delineamento experimental utilizado constou de fatorial $7 \times 2$, sendo sete tratamentos (testemunha; adição de sulfato de $\mathrm{Ca}$ e $\mathrm{Mg}$; calcário dolomítico; silicato de $\mathrm{Ca}$ e Mg; sulfato de $\mathrm{Ca}$ e $\mathrm{Mg}$ + esterco de curral; calcário dolomítico + esterco de curral; silicato de $\mathrm{Ca}$ e $\mathrm{Mg}$ + esterco de curral) e duas épocas de colheita, com quatro repetições, inteiramente casualizado (DIC). Verificou-se que a correção do solo mostrouse prática necessária para o desenvolvimento da Lippia citriodora. Independentemente da época de colheita, a produção de massa fresca e seca foi maior com a aplicação do esterco de curral (32 t ha $\left.{ }^{-1}\right)$, no entanto, isso não refletiu em maior rendimento de óleo essencial.
\end{abstract}

Palavras-chave: calcário, silicato, adubação orgânica

\begin{abstract}
Liming and organic fertilization on Lippia citriodora (Kunth) phytomass and essential oil production. The present work aimed to evaluate the effect of liming and bovine fertilization on Lippia citriodora Kunth phytomass and essential oil production. The experimental design was completely randomized with seven treatments (control; $\mathrm{Ca}$ and $\mathrm{Mg}$ sulfate; limestone; $\mathrm{Ca}$ and $\mathrm{Mg}$ silicate; $\mathrm{Ca}$ and $\mathrm{Mg}$ sulfate + manure; limestone + manure; $\mathrm{Ca}$ and $\mathrm{Mg}$ silicate + manure) and two harvest seasons, with four replicates. Soil adjustment showed to be a necessary procedure for Lippia citriodora development. Independently of the harvest season, fresh and dry matter yields were higher under treatments with bovine manure (32 $\left.\mathrm{t} \mathrm{ha}^{-1}\right)$; however, no effect of treatments was observed on essential oil concentration.
\end{abstract}

Key words: limestone, silicate, organic fertilization

\section{INTRODUÇÃO}

A Lippia citriodora Kunth é uma espécie originária da América do Sul, sendo conhecida popularmente no Brasil como cidrão, sendo muito utilizada na medicina caseira, principalmente devido à atividade medicinal das folhas. As propriedades fitoterapêuticas devem-se à presença de sesquiterpenos característicos do gênero Lippia (Guerrero, 2002): citral (30-35\%), limoneno (10-18\%), citroneol, alfa e beta pineno, etil-eugenol, linalol, entre outros (Lorenzi \& Matos, 2002) no óleo essencial. Na Europa, dentre as espécies de Verbenaceae, a Lippia citriodora é muito explorada comercialmente para produção de óleo essencial, conhecido como óleo de verbena, amplamente utilizado em perfumaria (Craveiro et al., 1981).

O desenvolvimento vegetal e, em especial, a produção de óleos essenciais em plantas aromáticas é influenciado por vários fatores ambientais, incluindo condições do solo. Nesse sentido, sabe-se que a maioria dos solos brasileiros é ácido, o que causa grande dificuldade para a produção vegetal. Além da alta saturação de alumínio, que pode apresentar efeitos tóxicos para as plantas, os solos ácidos normalmente contêm baixo teor de cálcio e de magnésio trocáveis. Uma das alternativas para contornar esse problema é a correção da acidez através da prática da calagem (Goedert et al., 1991).

Recebido para publicação em 14/03/2008

Aceito para publicação em 10/07/10

Rev. Bras. Pl. Med., Botucatu, v.12, n.4, p.401-405, 2010. 
Corrêa Júnior (1994) afirma que em muitos casos, a complementação da adubação orgânica, via adubos minerais, é fundamental quando se visa à produção adequada de plantas medicinais. Nesse sentido, para o cidrão, espécie ainda pouco estudada, além da adubação mineral e correção do solo, a resposta à adubação orgânica deve ser investigada tendo em vista a possibilidade de acréscimo na produção de biomassa e no rendimento de óleo essencial, além da reciclagem destes resíduos nas propriedades rurais e da recuperação das características físicas, químicas e biológicas do solo. Desta forma, Ming (1992), testando doses de adubação orgânica $\left(0 ; 1 ; 2 ; 4\right.$ e $8 \mathrm{~kg} \mathrm{~m}^{-2}$ de esterco bovino) em Lippia alba, verificou que o aumento nas doses de esterco bovino resultou em maiores rendimentos de biomassa, porém, em decréscimo no teor de óleo essencial.

Assim, o presente trabalho teve como objetivo avaliar a produção de biomassa e o teor de óleo essencial de Lippia citriodora (Lam.) em função da prática corretiva do solo, associada à adubação com esterco de curral curtido.

\section{MATERIAL E MÉTODO}

O trabalho foi conduzido em casa de vegetação no Instituto de Ciências Agrárias da Universidade Federal de Minas Gerais (ICA/UFMG), no município de Montes Claros-MG, no período de Agosto de 2006 a Março de 2007. Foram utilizados vasos com três litros de solo classificado como Latossolo Vermelho Amarelo distrófico típico, sob vegetação de Cerrado. Amostras de $0-20 \mathrm{~cm}$ de profundidade foram submetidas à caracterização de rotina. Os atributos químicos e físicos determinados conforme Embrapa (1997) foram: $\mathrm{pH}$ em água: 4,7; $\mathrm{P}: 1 \mathrm{mg} \mathrm{dm}^{-3} ; \mathrm{K}: 0,4 \mathrm{mmol}_{\mathrm{c}} \mathrm{dm}^{-3} ; \mathrm{Ca}: 1,0 \mathrm{mmol}_{\mathrm{c}} \mathrm{dm}^{-3}$; Mg: 0,4 mmol $\mathrm{cm}^{-3} ; \mathrm{Al}: 12,0 \mathrm{mmol}_{\mathrm{c}} \mathrm{dm}^{-3}$; matéria orgânica: $10,1 \mathrm{~g} \mathrm{~kg}^{-1}$; areia: $850 \mathrm{~g} \mathrm{~kg}^{-1}$; silte: $50 \mathrm{~g} \mathrm{~kg}^{-1}$; argila: $100 \mathrm{~g} \mathrm{~kg}^{-1}$. A análise química e física do esterco de curral curtido, conforme metodologia de Tedesco et al. (1995), apresentaram os seguintes resultados: umidade: 7,55; $\mathrm{pH}$ em água: 5,09; $\mathrm{N}$ total: 2,50\%; $\mathrm{P}_{2} \mathrm{O}_{5}: 1,05 \%$; $\mathrm{K}_{2} \mathrm{O}: 1,33 \%$; $\mathrm{CaO}: 1,41 \%$; $\mathrm{MgO}$ : 0,89 \%; S: 0,10 $\mathrm{g} \mathrm{kg}^{-1}$; B: 53,00 mg kg-1 Zn: 96,00 mg kg-1; Mn: 243,00 mg kg-1 e Cu: 40,00 mg kg-1.

O delineamento experimental utilizado foi 0 inteiramente casualizado em esquema fatorial $7 \times 2$ sendo sete tratamentos e duas épocas de coleta. Os tratamentos foram: T1 - Testemunha (solo natural); T2 - Aplicação de sulfato de Ca e Mg; T3 - Calcário dolomítico; T4 - Silicato de Ca e Mg; T5 - Sulfato de Ca e Mg + esterco curral curtido; T6 - Calcário dolomítico + esterco de curral curtido, e T7 - Silicato de $\mathrm{Ca}$ e $\mathrm{Mg}+$ esterco curral curtido, com quatro repetições. As doses de calcário e silicato de Ca foram estimadas para elevar a saturação por bases a $60 \%$, conforme Van Raij et al. (1997). O poder de neutralização do calcário utilizado é de $90 \%$ e do silicato de cálcio e magnésio de $86 \%$. As doses de $\mathrm{Ca}$ e Mg na forma de sulfato foram estimadas para a mesma quantidade de cálcio e magnésio do calcário dolomítico. O esterco de curral curtido utilizado foi seco a $65^{\circ} \mathrm{C}$, triturado e em seguida peneirado em malha de $1 \mathrm{~mm}^{2}$ de abertura. Aos 15 dias, antes do plantio das mudas nos vasos, aplicou-se uma dose de esterco equivalente a $32 \mathrm{t} \mathrm{ha}^{-1}$ (CFSEMG, 1999). Também à época, foi realizada adubação com fosfato de sódio $\left[\mathrm{NaH}_{2} \mathrm{PO}_{4} \cdot \mathrm{H}_{2} \mathrm{O}\right.$, p.a. $\left(300 \mathrm{mg} \mathrm{dm}^{-3}\right)$ como fonte de $\mathrm{P}]$, nitrato de amônio $\left[\mathrm{NH}_{4} \mathrm{NO}_{3}\right.$, p.a. $(100 \mathrm{mg}$ $\mathrm{dm}^{-3}$ ) como fonte de $\left.\mathrm{N}\right]$, cloreto de potássio [ $\mathrm{KCl}$ p.a. $\left(100 \mathrm{mg} \mathrm{dm}^{-3}\right.$ ) como fonte de $\mathrm{K}$ ] e sulfato de potássio $\left[\mathrm{K}_{2} \mathrm{SO}_{4}\right.$ p.a. $\left(40 \mathrm{mg} \mathrm{dm}^{-3}\right)$ como fonte de S]. Aumidade do solo foi mantida próxima à capacidade de campo do solo, calculada pela curva característica de água no solo. A quantidade de água adicionada por vaso foi de $1200 \mathrm{~mL}$, que correspondeu a $30 \%$ do volume do vaso.

As mudas utilizadas no presente estudo foram obtidas de estacas apicais (herbáceas ou semiherbáceas), com 8 a $10 \mathrm{~cm}$ de comprimento e 0,5 de diâmetro, coletadas da coleção do horto de plantas medicinais do ICA/UFMG. As estacas foram enraizadas em bandejas coletivas contendo substrato constituído de partes iguais de vermiculita e casca de arroz carbonizada. Após o enraizamento, as mudas foram selecionadas quanto ao tamanho e vigor (número de brotações), em seguida, transplantadas para os vasos. Em todos os tratamentos utilizou-se uma planta por vaso, onde a umidade permaneceu próxima à capacidade de campo, durante todo o período experimental, por meio de pesagens diárias de cada vaso e reposição da água.

Foram realizadas duas colheitas, uma no inicio da floração, aos 120 dias após o plantio das estacas (Novembro/2006) e outra aos 120 dias da primeira, considerando-se o desenvolvimento da rebrota, no mês de Março de 2007. As colheitas foram realizadas na parte da manhã e as plantas foram cortadas a cinco centímetros do solo. Em seguida, o material colhido foi submetido à secagem em estufa com circulação de ar a 35-40드 até massa constante para a determinação da matéria fresca da parte aérea.

Para a extração do óleo essencial, amostras do material fresco, contendo caules, folhas e flores (cerca de $100 \mathrm{~g}$ ), foram submetidas à extração. A extração do óleo essencial foi conduzida por meio da hidrodestilação em aparelho de Clevenger, por quatro horas, sendo o resultado expresso em g de óleo por $100 \mathrm{~g}$ de matéria seca. Após a extração, o resíduo vegetal foi seco em estufa para a determinação da matéria seca.

Os dados obtidos foram submetidos à análise

Rev. Bras. PI. Med., Botucatu, v.12, n.4, p.401-405, 2010. 
de variância, pelo programa SAEG 9.1, e quando houve significância pelo teste $F$, as médias foram comparadas pelo teste Tukey a $5 \%$ de probabilidade.

\section{RESULTADO E DISCUSSÃO}

Os tratamentos influenciaram significativamente as variáveis, como produção de massa da matéria fresca e seca e o teor de óleo essencial das plantas de Lippia citriodora (Tabela 1). Para as plantas do tratamento testemunha, observou-se já no início do experimento, uma paralisação no desenvolvimento vegetal, seguida de morte de todas as plantas deste tratamento, o que consequentemente, impossibilitou a produção de biomassa e de óleo essencial, nas épocas de coleta. Tais resultados indicam que a falta da aplicação de corretivos e nutrientes no solo limitaram o crescimento da Lippia citriodora. Assim, nas condições deste estudo, práticas corretivas no solo mostraram ser necessárias para o crescimento do cidrão. Tal como observado neste experimento, Blank et al. (2006), ao avaliarem o efeito da adubação química e da calagem na nutrição de Melissa officinalis (L.), verificaram que a ausência da calagem foi um fator limitante para o desenvolvimento da cultura, pois não houve sobrevivência das plantas nesse tratamento.

As produções de matéria fresca e seca apresentaram valores superiores com a aplicação do esterco de curral curtido, sendo esses valores superiores na segunda coleta com diferenças significativas entre os respectivos tratamentos (Tabela 1). Esta resposta não foi observada para a produção de óleo essencial, que apresentou valores maiores na primeira colheita.

A aplicação de calcário dolomítico e esterco de curral, proporcionaram maior produção de matéria fresca e seca devido à elevação do $\mathrm{pH}$ e consequentemente aumento na atividade microbiológica, seguida de mineralização e disponibilização dos nutrientes do esterco de curra (Andrade et al., 2002). Oliveira Junior et al. (2006), comparando o efeito da calagem e da adubação orgânica no crescimento e nutrição da arnica, também observaram que a aplicação do calcário dolomítico juntamente com esterco de curral curtido (260 litros de esterco de curral por metro cúbico de substrato), promoveram maior produção de matéria seca da parte aérea. Da mesma forma, Silva et al. (2002), trabalhando com Zingibre officinalis, também verificaram aumento da produção de matéria seca com o uso de adubos orgânicos.

TABELA 1. Produção de massa da matéria fresca e da matéria seca e teores de óleo essencial de plantas de Lippia citriodora Kunth, cultivadas em solo tratado com diferentes corretivos e esterco de curral curtido, em duas épocas de colheita.

\begin{tabular}{|c|c|c|c|c|c|c|}
\hline \multirow{3}{*}{ Tratamentos } & \multicolumn{2}{|c|}{$\begin{array}{c}\text { Massa fresca } \\
\left.\text { (g planta }^{-1}\right)\end{array}$} & \multicolumn{2}{|c|}{$\begin{array}{l}\text { Massa seca } \\
\left(\text { g planta }^{-1}\right)\end{array}$} & \multicolumn{2}{|c|}{$\begin{array}{c}\text { Teor de óleo } \\
(\%)\end{array}$} \\
\hline & & & & $2^{\underline{a}}$ & $1^{\mathrm{a}}$ & $2^{\mathrm{a}}$ \\
\hline & $1^{\text {a }}$ colheita & $2^{\underline{a}}$ colheita & $1^{\mathrm{a}}$ colheita & colheita & colheita & colheita \\
\hline Testemunha & - & - & - & - & - & - \\
\hline $\mathrm{Ca}$ e $\mathrm{Mg}^{1}$ & $18,25 \mathrm{c} \mathrm{A}$ & $15,25 \mathrm{c} \mathrm{B}$ & $8,00 \mathrm{cA}$ & $5,55 \mathrm{c} \mathrm{B}$ & 1,14 a $A$ & 0,70 a $B$ \\
\hline Calcário $^{2}$ & 20,00 c A & 17,80 c B & $7,50 \mathrm{c} \mathrm{A}$ & 6,80 с B & 1,42 a $A$ & 0,66 a $B$ \\
\hline Silicato $^{3}$ & 24,25 c A & 19,80 c B & $9,00 \mathrm{c} \mathrm{A}$ & 6,65 c B & 0,91 a $A$ & 0,60 a $B$ \\
\hline Ca e $\mathrm{Mg}^{1}$ + esterco & 51,75 ab B & 67,40 a $A$ & $14,00 \mathrm{ab} B$ & $17,50 \mathrm{ab} A$ & 1,21 a $A$ & 0,67 a $B$ \\
\hline Calcário $^{2}$ + esterco & 55,00 a $B$ & 92,20 a $A$ & 14,50 a B & 23,90 a A & 1,44 a $A$ & 0,82 a $B$ \\
\hline Silicato $^{3}+$ esterco & 35,75 bc B & $55,10 a b A$ & $10,25 \mathrm{bc} B$ & $15,90 \mathrm{ab} \mathrm{A}$ & 0,99 a $A$ & 0,77 a $B$ \\
\hline CV (\%) & 14,05 & 17,12 & 9,16 & 15,08 & 21,33 & 19,11 \\
\hline
\end{tabular}

${ }^{1}$ Sulfato de Ca e Mg; ${ }^{2}$ Calcário Dolomítico; ${ }^{3}$ Silicato de Ca e Mg. Médias seguidas da mesma letra, minúscula nas colunas e maiúscula nas linhas, não diferem entre si pelo teste de Tukey a $5 \%$ de probabilidade.

Rev. Bras. PI. Med., Botucatu, v.12, n.4, p.401-405, 2010. 
Entre os tratamentos sem a adição de esterco de curral, não foram verificadas diferenças significativas na produção de matéria fresca e seca, no entanto, na primeira colheita verificou-se maior produção, contrapondo o ocorrido para os tratamentos que receberam esterco (Tabela 1).

Pode-se inferir que além de melhorar as propriedades físicas, como estrutura e retenção de água pelo solo, químicas (fornecimento de nutrientes) e biológicas do solo, a aplicação de esterco bovino possibilitou aumento na produção devido à presença de substâncias húmicas de baixa massa molecular provenientes do composto orgânico, uma vez que todos os tratamentos receberam a mesma adubação básica com nutrientes na forma inorgânica. Na planta, as substâncias húmicas podem promover uma parcial fosforilação oxidativa nas mitocôndrias e atuarem como reguladores de crescimento, aumentando a produção de biomassa (Visser, 1987; Canellas et al., 2002). Silva et al. (2007), trabalhando com Macrotyloma axillare, verificaram que a maior produção obtida nos tratamentos que receberam esterco bovino foi devido às melhorias das propriedades físicas químicas e biológicas do solo, uma vez que os nutrientes foram aplicados na forma inorgânica em todos os tratamentos estudados.

O teor de óleo essencial não foi influenciado pelas práticas corretivas do solo ou pela adição de esterco de curral curtido, no entanto, a época da colheita influenciou significativamente a produção (Tabela 1). Apesar de ter produzido maior quantidade de massa fresca e seca na presença do esterco de curral, isso não refletiu em maior produção de óleo essencial. A redução do teor de óleo essencial das plantas na segunda coleta pode estar relacionada ao efeito de diluição, devido à maior produção de ramos e folhas. Esses resultados estão de acordo com o exposto em Ming (1992), que também verificou aumento no rendimento de biomassa e decréscimo no teor de óleo essencial em Lippia alba sob doses de esterco de curral. Segundo Sangwan et al. (2001), a aplicação de fertilizantes minerais ou orgânicos em plantas aromáticas normalmente afeta a produtividade de óleos essenciais devido ao maior acúmulo de biomassa. Entretanto, Silva et al. (2003), trabalhando com adubos orgânico e mineral sobre a produção de biomassa e óleo essencial de capim-limão, verificaram que os diferentes adubos orgânicos testados não influenciaram o teor de óleo essencial. Da mesma forma, Santos \& Innecco (2004) verificaram que a produção de óleo essencial em folhas Lippia alba também não foi influenciada pela adubação orgânica.

\section{CONCLUSÃO}

A correção do solo mostrou-se prática necessária para o desenvolvimento da Lippia citriodora.

A produção de matéria fresca e seca foram maiores com a aplicação do esterco de curral, no entanto, isso não refletiu em maior teor de óleo essencial.

\section{REFERÊNCIA}

ANDRADE, A.T.; FERNANDES, L.A.; FAQUIN, V. Organic residue, limestone, gypsum and phosphorus adsorption by lowland soils. Scientia Agricola, v.59, p.349-55, 2002. BLANK, A.F. et al. Efeitos da adubação química e da calagem na nutrição de melissa e hortelã-pimenta. Horticultura Brasileira, v.24, p.195-8, 2006.

CANELLAS, L.P. et al. Humic acids isolated from earthworm compost enhance root elongation, lateral root emergence, and plasma membrane $\mathrm{H}^{+}$- ATPase activity in maize roots. Plant Physiology, v.130, p.1951-7, 2002. COMISSÃO DE FERTILIDADE DO SOLO DO ESTADO DE MINAS GERAIS. Adubação orgânica. In: RIBEIRO, A.C.; GUIMARÃES, P.T.G; ALVAREZ, V.H. (Eds.). Recomendação para o uso de corretivos e fertilizantes em minas gerais. Viçosa: Sociedade Brasileira de Ciência do Solo, 1999. p.87-92.

CORRÊA JÚNIOR, C. Influência das adubações orgânica e química na produção de camomila [Chamomilla recutita (L.) Raucschert] e do seu óleo essencial. 1994. 95p. Dissertação (Mestrado - Área de Concentração em Agricultura) - Departamento de Agronomia, Universidade Estadual de Paulista, Botucatu. CRAVEIRO, A. A. et al. Óleos essenciais de plantas do nordeste. UFC: Fortaleza, 1981. 210p.

EMPRESA BRASILERIA DE PESQUISA AGRICOLA. Serviço Nacional de Levantamento e Conservação de Solo. Manual de métodos de análise de solo. Rio de Janeiro: Ministério da Agricultura, 1997. 212p.

GOEDERT, W.J.; SOUZA, D.M.G.; SCOLARI, D.O.G. Critérios para recomendação de calagem e adubação. In: OLIVEIRA, A.J. et al. (Coords.). Métodos de pesquisa em fertilidade do solo. Brasília: EMBRAPA-SEA, 1991. p.363-92.

GUERRERO, M.F. et al. Assessment of the antihypertensive and vasodilator effects of ethanolic extracts of some Colombian medicinal plants. Journal of Ethnopharmacology, v.80, p.37-42, 2002.

LORENZI, H.; MATOS, F.J.A. Plantas medicinais no Brasil: nativas e exóticas cultivadas. Nova Odessa: Instituto Plantarum, 2002. 512p.

MARSCHNER, H. Mineral nutrition of higher plants. London: Academic Press, 1995. 889p.

MING, L.C. Influência de diferentes níveis de adubação orgânica na produção de biomassa e teor de óleos essenciais de Lippia alba (Mill.) N.E. Br. Verbenaceae. 1992. 206p. Dissertação (Mestrado - Área de Concentração em Produção Vegetal) - Departamento de Fitotecnia e Fitossanitarismo, Universidade Federal do Paraná, Curitiba.

OLIVEIRA JÚNIOR, A.C.; FAQUIN, V.; PINTO, J.E.B.P.

Rev. Bras. PI. Med., Botucatu, v.12, n.4, p.401-405, 2010. 
Efeitos de calagem e adubação no crescimento e nutrição de arnica. Horticultura Brasileira, v.24, p.34751, 2006.

SANGWAN, N.S. et al. Regulation of essential oil production in plants. Plant Growth Regulation, v.6, n.34, p.3-21, 2001.

SANTOS, M.R.A.; INNECCO, R. Adubação orgânica e altura de corte da erva-cidreira brasileira. Horticultura Brasileira, v.22, p.182-5, 2004.

SILVA, M.A.S. et al. Efeitos da adubação orgânica e da cobertura morta na produtividade de gengibre (Zingiber officinale Rosc.). In: SIMPÓSIO DE PLANTAS MEDICINAIS DO BRASIL, 17., 2002, Cuiabá. Resumos... Cuiabá: Universidade Federal do Mato Grosso, 2002. CD-ROM. SILVA, P.A. et al. . Efeitos da adubação orgânica e mineral na produção de biomassa e óleo essencial do capimlimão [Cymbopogon citratus (DC.) Stapf]. Ciência Agronômica, v.34, p.92-6, 2003.

SILVA, A.H. et al. O uso de Macrotyloma axillare em processos de recuperação de áreas degradadas: técnicas de cultivo e adubação no Norte de Minas Gerais. Revista Caminhos da Geografia, v.8, p.105-15, 2007. TEDESCO, M.J. et al. Análise de solo, planta e outros materiais. Porto Alegre: UFRGS, 1995. 174p.

VAN RAIJ, B. et al. (Eds.). Recomendações de adubação e calagem para o Estado de São Paulo. 2.ed. Campinas: IAC, 1997. 285p. (Boletim Técnico, 100)

VISSER, S.A. Effect of humic substances on mitochondrial respiration and oxidative phosphorylation. The Science of the Total Enviroment, v.62, p.347-54, 1987. 